\title{
PROPOSTA DE UMA FERRAMENTA DE AVALIAÇÃO DE USABILIDADE PARA VESTUÁRIO INCLUSIVO UTILIZANDO A METODOLOGIA OIKOS
}

\section{PROPOSAL OF AN USABILITY EVALUATION TOOL FOR INCLUSIVE CLOTHING USING OIKOS METHODOLOGY}

\author{
Tatiana Castro Longhi ${ }^{1}$, Bach. \\ Flávio Anthero Nunes Vianna dos Santos², Dr. \\ Milton José Cinelli ${ }^{3}$ Dr. \\ (1) Universidade do Estado de Santa Catarina (UDESC) \\ e-mail: dilonghi@gmail.com \\ (2) Universidade do Estado de Santa Catarina (UDESC) \\ e-mail: flavioanvs@hotmail.com \\ (3) Universidade do Estado de Santa Catarina (UDESC) \\ e-mail: milton.cinelli@udesc.br
}

Palavras-chave: pessoa com deficiência, vestuário inclusivo, usabilidade.

O artigo apresenta requisitos para o vestuário inclusivo de cadeirantes, idosos e deficientes visuais, através de uma ferramenta de avaliação de usabilidade de vestuário, adaptada da Metodologia OIKOS. A ferramenta permite a verificação da usabilidade junto aos usuários das peças e, nos pontos em que forem identificados problemas, retificar o projeto antes da sua produção, comercialização e divulgação.

\section{Key-words: person with disabilities, inclusive apparel, usability.}

The article presents requirements for the inclusive apparel of wheelchair users, the elderly and the visually impaired, through a tool of usability evaluation of apparel, adapted from the OIKOS Methodology. The tool allows usability testing with users and where problems are identified, rectify the project before its production, marketing and disclosure.

\section{Introdução}

A usabilidade é uma qualidade inerente a muitos produtos, mas segundo Rubin e Chisnel (2008), frequentemente ela está ausente. São diversas as razões para isso, podendo ser históricas, culturais, organizacionais, financeiras, entre outras. No entanto, existem métodos confiáveis que permitem avaliar a usabilidade de um produto e definir o que precisa ser remodelado para que esse tenha o desempenho adequado. 


\section{$16^{\circ}$ \\ ERGODESIGN USIHC CINAHPA}

É mais fácil identificar a falta de usabilidade de um produto do que a presença dela. Essa ausência de usabilidade pode ser enfrentada por qualquer indivíduo durante a sua interação com qualquer produto ou sistema, inclusive com o vestuário, que é parte do dia a dia de todas as pessoas e pode se adequar a diversos usos.

A produção industrial massificada fabrica peças com foco no maior número de usuários possível. $\mathrm{O}$ indivíduo com deficiência, por sua vez, possui necessidades que podem diferir das outras pessoas em maior ou menor grau, em função das suas condições de saúde, suas habilidades e suas limitações. Nesse ponto, os idosos também podem apresentar as mesmas características em relação ao vestuário, pois em função das suas condições de saúde, podem vir a necessitar de produtos especiais que facilitem a sua rotina.

Por ser tão presente na vida de todas as pessoas, $o$ vestuário não atua apenas no quesito funcionalidade, isso porque as pessoas com deficiência, assim como as pessoas sem deficiência, também desejam se apresentar para os outros e para si de forma alegre, bonita, lúdica, etc. $O$ vestuário então desempenha um papel crítico na vida desses indivíduos, pois pode ser uma barreira ou um facilitador, tanto na rotina prática do uso, como na expressão pessoal de cada um.

Outros aspectos precisam ser levados em conta, tais como a faixa etária da pessoa e se ela nasceu com a deficiência, ou se esta foi adquirida. A falta de usabilidade do vestuário para indivíduos em condições especiais pode causar dificuldades na manutenção da sua aparência, gerando insegurança e frustração. Segundo Woltz e Carvalho (2008), no momento em que uma pessoa se vê privada de usar as roupas que costuma usar, tem parte da capacidade de se expressar por meio do vestuário prejudicada. A desenvoltura na interação social também diminui, já que o vestuário é uma forma de pertencimento de um indivíduo ao seu grupo.

Baseado no tipo de deficiência, existente desde o nascimento ou resultado de um acidente, essas pessoas podem parecer e se comportar de forma $16^{\circ}$ Ergodesign - Congresso Internacional de Ergonomia e Usabilidade de Interfaces Humano Tecnológica: Produto, Informações Ambientes Construídos e Transporte

$16^{\circ}$ USIHC - Congresso Internacional de Ergonomia e Usabilidade de Interfaces Humano Computador

CINAHPA | 2017 - Congresso Internacional de Ambientes Hipermídia para Aprendizagem.

diferente. Assim, as deficiências geralmente são classificadas basicamente em deficiência física e/ou mental.

Deficiências físicas incluem cegueira, surdez e deficiências ortopédicas. Deficiências acidentais são aqueles que uma pessoa adquire no decorrer da vida, por exemplo, membro amputado resultante do serviço militar ou acidente de trabalho.

Deficiências mentais incluem problemas neurológicos e distúrbios de aprendizagem, por exemplo, Transtorno de Déficit de Atenção com Hiperatividade (TDAH), autismo e paralisia cerebral. (CHANG, HODGES e YURCHISIN, 2014).

De acordo com Woltz e Carvalho (2008), no que concerne ao vestuário, frequentemente quando existem peças próprias para deficientes físicos, as modificações feitas para responder às necessidades especiais dos usuários são bastante aparentes, podendo evidenciar ainda mais as deficiências. Assim, muitos desses usuários, não querem comprar roupas especiais para deficientes por receio de serem rotulados em função da aparência desses produtos.

\section{Usabilidade em produtos}

De acordo com Tullis e Albert (2008), a International Standards Organization (ISO 924111) destaca três aspectos da usabilidade e a define como "a extensão com que um produto pode ser usado por usuários específicos para atingir objetivos específicos com eficácia, eficiência e satisfação em um contexto específico de uso".

A definição da Associação de Profissionais de Usabilidade (UPA), por sua vez, baseia-se no processo de desenvolvimento de produto, pois considera a usabilidade como uma abordagem de desenvolvimento de produto que incorpora o feedback do usuário durante todo o ciclo de desenvolvimento, para reduzir custos e criar produtos e ferramentas que atendam às necessidades do usuário.

Muito do que torna algo utilizável, para Rubin e 


\section{$16^{\circ}$ \\ ERGODESIGN USIHC CINAHPA}

$16^{\circ}$ Ergodesign - Congresso Internacional de Ergonomia e Usabilidade de Interfaces Humano Tecnológica: Produto, Informações Ambientes Construídos e Transporte

$16^{\circ}$ USIHC - Congresso Internacional de Ergonomia e Usabilidade de Interfaces Humano Computador

CINAHPA | 2017 - Congresso Internacional de Ambientes Hipermídia para Aprendizagem.
Chisnel (2008), é a ausência de frustração em usálo, que este produto seja verdadeiramente útil, que o usuário possa utilizá-lo da forma como espera ser capaz de fazê-lo, sem entraves, hesitação ou dúvidas.

Para Jordan (1998), um produto que é usável para uma pessoa pode não ser para outra. Assim, a usabilidade depende em grande medida da pessoa que está usando o produto, o seu objetivo ao usá-lo e o ambiente de uso. Assim, a usabilidade é uma propriedade da interação entre o usuário e a tarefa que ele está tentando completar. Essa interação depende de alguns fatores, tais como a experiência prévia de uso do produto, traços culturais, idade e gênero.

Usabilidade é geralmente considerada a capacidade do usuário de usar algo para realizar uma tarefa com êxito, considerando que a experiência do usuário leva a uma visão mais ampla, a olhar para a interação de todo o indivíduo com o objeto e o ambiente, bem como os pensamentos, sentimentos e percepções que resultam dessa interação. Diante disso, para que seja possível medir a usabilidade de algo, é preciso considerar a experiência do usuário por completo. Isso porque a falta de usabilidade em alguns produtos pode prejudicar o desempenho e a saúde do indivíduo. (TULLIS e ALBERT, 2008).

Existe uma série de métodos para que se possa medir a usabilidade de algo e, para Jordan (1998), existem métodos empíricos e não empíricos. Entre os métodos empíricos estão: entrevistas, observação de campo, grupo focal, avaliação de usabilidade. Em Rubin e Chisnel (2008), além desses encontram-se a pesquisa etnográfica, design participativo, avaliação heurística, entre outros.

Para que um estudo de usabilidade atinja seus objetivos, Tullis e Albert (2008) destacam a importância de um bom planejamento prévio. É fundamental definir a quantidade e o tipo de participantes necessários ao estudo. No caso de pessoas com deficiência, um cuidadoso delineamento torna-se ainda mais necessário, considerando-se aspectos como o tipo de deficiência, grau de acometimento, bem como acesso aos sujeitos da pesquisa.

\section{Metodologia}

O processo metodológico dessa pesquisa foi dividido em três fases. Inicialmente, procedeu-se ao levantamento bibliográfico acerca dos temas usabilidade, pessoas com deficiência e vestuário inclusivo.

O recorte da pesquisa limitou-se aos usuários cadeirantes, deficientes visuais e idosos com algum acometimento de saúde. A seguir, foi possível construir uma série de requisitos sugeridos para a construção de vestuário adaptado às demandas de cada público. Após a definição dos critérios para o desenvolvimento de vestuário inclusivo, procedeuse a construção de uma ferramenta de avaliação de usabilidade voltada para o vestuário inclusivo. Essa ferramenta é uma adaptação da Metodologia para Avaliação da Usabilidade e Conforto no Vestuário, de Martins (2005).

\section{Requisitos para o desenvolvimento de vestuário inclusivo}

Cada ser humano é único e no caso de pessoas com deficiência, mesmo em grupos de pessoas que apresentam um quadro clínico semelhante de acometimento, essas diferenças se acentuam. Entretanto, o vestuário padrão utilizados pelas pessoas sem deficiências graves apresenta muitos entraves à vida da pessoa com deficiência e é nesse sentido que o presente artigo pretende reunir requisitos mínimos que favoreçam o desenvolvimento de vestuário inclusivo. Esses requisitos farão parte da proposta de avaliação de usabilidade para vestuário inclusivo para cada uma das categorias abrangidas, tais como: a)Cadeirantes; b)Idosos; c)Deficientes visuais.

\section{1 a) Cadeirantes}

De acordo com Brogin (2015), uma das maiores dificuldades dos cadeirantes reside no fato de utilizarem o vestuário na posição sentada, na maior parte do tempo do convívio diário. Esse fato influencia, por exemplo, nas dimensões antropométricas do indivíduo, uma vez que as
Realização:

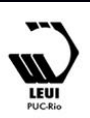




\section{$16^{\circ}$ \\ ERGODESIGN USIHC CINAHPA}

dimensões de cintura e quadris encontram-se ampliadas em função da pressão do próprio corpo sentado, o que amplia as medidas nessas regiões.

Outro destaque em relação à posição sentada refere-se ao cós e ao gancho das calças, que deve ser mais alto atrás e mais curto na frente, transpondo a lógica da distribuição de medidas em função da posição sentada. No quadro seguinte é possível visualizar essas e demais demandas.

As fontes que forneceram dados para a composição da Tabela 1 são parte da pesquisa de Brogin (2015). São elas: Matos et al. (2007), Costa (2011), Smith e Dangiolo (2009), Cunha e Broega (2009), Adans (2002), Maffei (2010), Carvalho (2007), Woltz (2007) e Pacific Northwest Cooperative Extension (1983).

\begin{tabular}{|c|c|c|}
\hline \multicolumn{3}{|c|}{ Requisitos para vestuário inclusivo - a) Cadeirantes } \\
\hline Tipo de peça & EVITAR & ADOTAR \\
\hline $\begin{array}{l}\text { Blusa, } \\
\text { camisa }\end{array}$ & $\begin{array}{l}\text { Casas de botões; } \\
\text { mangas boca de } \\
\text { sino ou cheias de } \\
\text { detalhes no pulso. }\end{array}$ & $\begin{array}{l}\text { Velcro p/ aberturas; botões } \\
\text { magnéticos; mangas e costas } \\
\text { mais largas; manga raglan; } \\
\text { camisa com pregas nas } \\
\text { costas; aberturas laterais; } \\
\text { abertura nas costas. }\end{array}$ \\
\hline $\begin{array}{l}\text { Calça, } \\
\text { bermuda }\end{array}$ & $\begin{array}{l}\text { Evitar bolsos na } \\
\text { parte de trás; boca } \\
\text { da calça estreita. }\end{array}$ & $\begin{array}{l}\text { Velcro p/ aberturas; botões } \\
\text { magnéticos; cós mais alto } \\
\text { atrás e mais curto na frente; } \\
\text { aberturas na frente; bolsos } \\
\text { com velcro p/ fechar; } \\
\text { elástico na cintura; ribana na } \\
\text { barra da calça; ganchos p/ } \\
\text { abertura; abertura nas } \\
\text { laterais, a partir do cós e até } \\
\text { pouco acima do joelho. }\end{array}$ \\
\hline Saia, vestido & $\begin{array}{l}\text { zíper, botões na } \\
\text { parte de trás. }\end{array}$ & $\begin{array}{l}\text { Velcro para aberturas; } \\
\text { comprimento mínimo logo } \\
\text { acima do joelho; abertura } \\
\text { frontal em zíper destacável } \\
\text { (maior de } 25 \mathrm{~cm} \text { ). }\end{array}$ \\
\hline Outros & & $\begin{array}{l}\text { Protetores de cotovelo; } \\
\text { aviamentos e colchetes } \\
\text { grandes; zíper de dupla } \\
\text { abertura. }\end{array}$ \\
\hline Acabamentos & $\begin{array}{l}\text { Excesso de } \\
\text { costuras internas; } \\
\text { costuras grossas. }\end{array}$ & $\begin{array}{l}\text { Uso de pences e pregas em } \\
\text { locais necessários; costuras } \\
\text { internas embutidas. }\end{array}$ \\
\hline Tecidos & $\begin{array}{l}\text { Emborrachados; } \\
\text { rijos; ásperos; que } \\
\text { não esticam; } \\
\text { volumosos; muito } \\
\text { escorregadios. }\end{array}$ & $\begin{array}{l}\text { Malhas; algodão; } \\
\text { termorreguladores; boa } \\
\text { elasticidade; deslizantes; } \\
\text { leves; resistentes; toque } \\
\text { suave; absorventes. }\end{array}$ \\
\hline Modelagem & $\begin{array}{l}\text { Muito ajustada ao } \\
\text { corpo. }\end{array}$ & $\begin{array}{l}\text { Um pouco mais ampla na } \\
\text { cintura, quadris e coxas; } \\
\text { costura lateral deslocada p/ } \\
\text { frente; espaço p/ cateteres e } \\
\text { bolsas de colostomia. }\end{array}$ \\
\hline Aviamentos & $\begin{array}{l}\text { Peças de difícil } \\
\text { manuseio; } \\
\text { materiais de baixa }\end{array}$ & $\begin{array}{l}\text { Aviamentos e colchetes } \\
\text { grandes; zíper de dupla } \\
\text { abertura. }\end{array}$ \\
\hline
\end{tabular}

$16^{\circ}$ Ergodesign - Congresso Internacional de Ergonomia e Usabilidade de Interfaces Humano Tecnológica: Produto, Informações Ambientes Construídos e Transporte

$16^{\circ}$ USIHC - Congresso Internacional de Ergonomia e Usabilidade de Interfaces Humano Computador

CINAHPA | 2017 - Congresso Internacional de Ambientes Hipermídia para Aprendizagem.

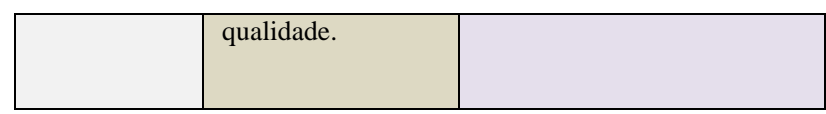

Tabela 1- Requisitos para vestuário inclusivo de cadeirantes.

Fonte: elaborado pelos autores.

\section{2 b) Idosos}

Segundo Chang, Hodges e Yurchisin (2014) deficiência pode ser definida como qualquer falta de capacidade de executar uma atividade que é considerada normal para um ser humano em uma sociedade particular. Assim, idosos também podem sentir uma crescente dificuldade em relação ao vestuário, especialmente em seus aspectos funcionais.

De acordo com Laville e Volkoff (2012 apud Melo, 2013) os efeitos do processo de envelhecimento são diversos. Alguns deles são: redução da capacidade de esforço físico; enfraquecimento do sistema de equilíbrio do corpo; diminuição da visão e da audição; enfraquecimento da memória etc. Assim, as limitações que acometem os idosos possivelmente irão interferir na sua interação com os artefatos industriais.

Muitos dos usuários idosos apresentam algum tipo de dificuldade na interação com produtos industrializados. Assim, um objeto projetado para o público em geral, pode não ser tão adequado ao usuário idoso. Considerando as dificuldades físicas e cognitivas decorrentes das degenerações e doenças típicas da idade, é importante que os projetistas e pesquisadores de design busquem soluções que não excluam esse público. (MELO, 2013).

É importante distinguir as diferenças que podem existir entre os indivíduos considerados idosos, uma vez que existem idosos ativos e independentes, assim como também existem idosos com necessidades especiais, com deficiências motoras e/ou psíquicas. As faixas de idade neste mercado são representativas, uma vez que alteram significativamente as necessidades deste público, pois uma pessoa de 80 anos possui necessidades diferenciadas de uma de 60 anos. 


\section{$16^{\circ}$ \\ ERGODESIGN USIHC CINAHPA}

No que tange à escolha dos tecidos, os tecidos tecnológicos, amplamente utilizados no segmento esportivo, podem ser uma alternativa ao vestuário de pessoas com necessidades especiais. Esses tecidos "inteligentes" têm funções relevantes, como: bacteriostática, anti-odores, antialérgicos, com proteção UVA e UVB, hidro-repelentes, antimanchas e de fácil higienização.

No quadro seguinte (Tabela 2) são apresentados requisitos para o vestuário inclusivo de idosos. É possível observar a semelhança em alguns pontos com os requisitos desenvolvidos para os cadeirantes, pois esses usuários encontram dificuldades semelhantes em alguns momentos da sua interação com o vestuário. No caso dos idosos que utilizam cadeira de rodas os requisitos para cadeirantes devem ser considerados; para os idosos que caminham, mesmo com o auxílio de bengalas ou andadores, pode-se considerar a Tabela 2, uma vez que esses indivíduos alternam as suas posições entre de pé e sentados.

\begin{tabular}{|c|c|c|}
\hline \multicolumn{3}{|c|}{ Requisitos para vestuário inclusivo - b) Idosos } \\
\hline Tipo de peça & EVITAR & ADOTAR \\
\hline $\begin{array}{l}\text { Blusa, } \\
\text { camisa }\end{array}$ & $\begin{array}{l}\text { Casas de botões; } \\
\text { mangas boca de } \\
\text { sino ou cheias de } \\
\text { detalhes no pulso. }\end{array}$ & $\begin{array}{l}\text { Velcro p/ aberturas; botões } \\
\text { magnéticos; aberturas } \\
\text { laterais; abertura nas costas. }\end{array}$ \\
\hline $\begin{array}{l}\text { Calça, } \\
\text { bermuda }\end{array}$ & $\begin{array}{l}\text { Boca da calça } \\
\text { estreita. }\end{array}$ & $\begin{array}{l}\text { Velcro p/ aberturas; botões } \\
\text { magnéticos; aberturas atrás; } \\
\text { bolsos com velcro p/ fechar; } \\
\text { elástico na cintura; ganchos p/ } \\
\text { abertura; abertura nas laterais, } \\
\text { do cós até pouco acima do } \\
\text { joelho. }\end{array}$ \\
\hline Saia, vestido & Zíper metálico & $\begin{array}{l}\text { Velcro para aberturas; } \\
\text { comprimento mínimo na } \\
\text { altura do joelho; abertura } \\
\text { frontal em zíper destacável } \\
\text { (maior de } 25 \mathrm{~cm} \text { ) }\end{array}$ \\
\hline Outros & & $\begin{array}{l}\text { Aviamentos e colchetes } \\
\text { grandes }\end{array}$ \\
\hline Acabamentos & $\begin{array}{l}\text { Excesso de costuras } \\
\text { internas; costuras } \\
\text { grossas. }\end{array}$ & Costuras internas embutidas. \\
\hline Tecidos & $\begin{array}{l}\text { Emborrachados; } \\
\text { rijos; ásperos; que } \\
\text { não esticam; } \\
\text { volumosos; muito } \\
\text { escorregadios. }\end{array}$ & $\begin{array}{l}\text { Malhas; algodão; } \\
\text { termorreguladores; boa } \\
\text { elasticidade; deslizantes; } \\
\text { leves; resistentes; toque } \\
\text { suave; absorventes. }\end{array}$ \\
\hline Modelagem & $\begin{array}{l}\text { Muito ajustada ao } \\
\text { corpo. }\end{array}$ & $\begin{array}{l}\text { Espaço p/ cateteres, fralda } \\
\text { geriátrica e bolsa de } \\
\text { colostomia. }\end{array}$ \\
\hline Aviamentos & $\begin{array}{l}\text { Peças de difícil } \\
\text { manuseio; materiais } \\
\text { de baixa qualidade. }\end{array}$ & $\begin{array}{l}\text { Aviamentos e colchetes } \\
\text { grandes. }\end{array}$ \\
\hline
\end{tabular}

$16^{\circ}$ Ergodesign - Congresso Internacional de Ergonomia e Usabilidade de Interfaces Humano Tecnológica: Produto, Informações Ambientes Construídos e Transporte

$16^{\circ}$ USIHC - Congresso Internacional de Ergonomia e Usabilidade de Interfaces Humano Computador

CINAHPA | 2017 - Congresso Internacional de Ambientes Hipermídia para Aprendizagem.

Tabela 2 - Requisitos para vestuário inclusivo de idosos. Fonte: elaborado pelos autores.

\section{3 c) Deficientes visuais}

O vestuário pode ser percebido pelo ser humano por meio dos sentidos - visão, olfato e tato, com destaque para a visão. Quando há privação deste sentido, surgem dificuldades em identificar cores, modelos e funcionalidades do vestuário em geral. Assim, a independência do indivíduo fica seriamente comprometida.

Uma iniciativa de uma empresa de Petrópolis/RJ com o apoio da FAPERJ (Fundação Carlos Chagas Filho de Amparo à Pesquisa do Estado do Rio de Janeiro) foi desenvolvida a fim de tornar a escolha do vestuário uma atividade mais rápida e prática para os deficientes visuais.

O cabide possui um chip, onde são gravadas mensagens sonoras de 20 segundos com as características da peça, como detalhes de cor, formato da roupa, tipo de tecido e até para qual clima o vestuário é mais apropriado. Para acionar o "cabide falante", que é feito de resina e madeira reciclada, é preciso apertar um botão localizado abaixo do gancho. (MEDINA, 2013).

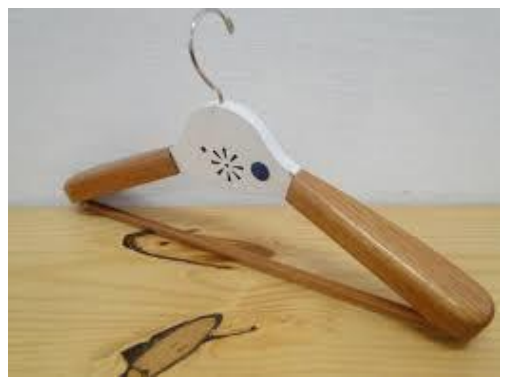

Figura 1 - Cabide de roupas sonoro para deficientes visuais. Fonte:

http://www.rj.gov.br/web/imprensa/exibeconteudo?articl e-id=1445396 Acesso em: 25 nov. 2015.

O protótipo do "cabide-visão" foi testado pelos deficientes visuais da Associação Brasileira de Assistência ao Deficiente Visual (Laramara), em São Paulo. 


\section{$16^{\circ}$ \\ ERGODESIGN USIHC CINAHPA}

Os participantes apreciaram o projeto e se emocionaram com a iniciativa, além de sugerirem a expansão da ideia para outras áreas do cotidiano. Há também outra versão mais simples do produto, em que uma fita preenchida em braile traz as descrições das roupas. (MEDINA, 2013).

Outra iniciativa no sentido de facilitar a interação dos deficientes visuais com o vestuário é a de Borin e Almeida (2008). Os estudantes de Engenharia Elétrica desenvolveram um circuito permite a gravação e posterior reprodução da voz do usuário.

Ao passar a etiqueta da roupa por um leitor ligado ao circuito, o usuário pode saber qual peça é a escolhida. O sistema possibilita a identificação de objetos por meio de um leitor e etiquetas que podem ser colocadas em roupas. (BORIN e ALMEIDA, 2008).

O equipamento foi feito com o objetivo de ajudar deficientes visuais na escolha das roupas, acessórios e na identificação de outros objetos. A ideia do projeto surgiu do contato com o Instituto Paranaense de Cegos, que identificava a necessidade dos deficientes visuais em combinar as roupas que vão usar. Além do circuito que permite a identificação, foi escolhido um tipo de etiqueta com um código numérico inscrito. Com o tamanho de um botão de camisa, uma vez na roupa, permite a lavagem e a passadoria sem danificar a peça. Utilizando tecnologia de identificação por rádio frequência (RFID), independentemente da posição em que o leitor seja posicionado, poderá ler o que há na etiqueta, diferente do que acontece com os códigos de barra, em que o leitor deve ser posicionado sobre o código e no sentido das barras, para que haja a leitura. (BORIN e ALMEIDA, 2008).

Diante do exposto até aqui, pode-se inferir que a principal barreira do deficiente visual perante o vestuário seria em termos da percepção do produto. Iniciativas que permitem a leitura por meio de etiquetas em braile ou a vocalização dos aspectos inerentes às peças podem vir a ser suficientes para permitir uma interação destes usuários com o vestuário. Assim, não será apresentado o quadro de $16^{\circ}$ Ergodesign - Congresso Internacional de Ergonomia e Usabilidade de Interfaces Humano Tecnológica: Produto, Informações Ambientes Construídos e Transporte

$16^{\circ}$ USIHC - Congresso Internacional de Ergonomia e Usabilidade de Interfaces Humano Computador

CINAHPA | 2017 - Congresso Internacional de Ambientes Hipermídia para Aprendizagem.

requisitos para vestuário inclusivo nesta categoria.

Uma pesquisa mais aprofundada acerca da interação entre esses usuários e o vestuário poderia fundamentar um estudo desses requistos, verificando se há ou não demandas relativas à usabilidade.

\section{Metodologia OIKOS}

A metodologia OIKOS é uma proposta para avaliação de usabilidade em artigos de vestuário e baseia-se na ideia de que a roupa está ligada ao conforto, aconchego e proteção, daí o nome de origem grega que significa "casa", "casulo". Tratase de um método de prevenção, devendo ser utilizado desde as fases iniciais do projeto de produto, como a concepção e o desenvolvimento, passando por todas as etapas do projeto, a fim de verificar se o produto atende a todos os requisitos ergonômicos necessários a satisfação do usuário final. (MARTINS, 2008).

Para desenvolver essa metodologia, Martins (2005) pesquisou os princípios de usabilidade de Nielsen (1993), Stanton e Young (1998) e Jordan (1998).

Especialmente Jordan (1998) consta na metodologia por meio dos "indicadores de usabilidade". Utilizou os estudos de classificação de conforto em têxteis de Nicolini (1995), para classificação de vestuário, no qual define três categorias de conforto:

Conforto físico: sensações provocadas pelo contato do tecido com a pele. Também engloba o ajuste do produto no corpo, em posições estáticas e dinâmicas.

Conforto fisiológico: remete a capacidade que o vestuário possui de interferir no metabolismo do corpo, como a parte térmica e hidrodinâmica.

Conforto psicológico: está ligado à estética (cores, formas, texturas, materiais); à personalidade do indivíduo; ao contexto de uso em sociedade; às tendências de moda.

A avaliação de usabilidade da metodologia OIKOS, segundo Martins (2005) deve ser feita no
Realização:

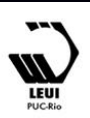




\section{$16^{\circ}$ \\ ERGODESIGN USIHC CINAHPA}

contexto de uso de cada peça de vestuário investigada e a pontuação dada pelos usuários, por meio de checklist, numa escala de 0 a 100.

\section{Resultados}

A interação dos usuários em geral com o vestuário industrial costuma apresentar uma série de questões. Essa interação é mais difícil ainda para pessoas com deficiências ou idosos. Em função das dificuldades apontadas por pesquisas acerca da interação entre as pessoas com deficiência e o vestuário padrão, identificou-se a necessidade de desenvolvimento de um vestuário adaptado às necessidades de cada grupo de indivíduos.

Com base na tese de Martins (2005), que apresenta uma Metodologia para Avaliação da Usabilidade e Conforto no Vestuário (OIKOS), elaborou-se a Tabela 3 a seguir.

\begin{tabular}{|c|c|c|c|c|c|c|c|}
\hline \multirow{2}{*}{$\begin{array}{l}\text { Proprie- } \\
\text { dades } \\
\text { Ergonô- } \\
\text { micas, } \\
\text { Usabili- } \\
\text { dade e } \\
\text { Conforto }\end{array}$} & \multirow[t]{2}{*}{$\begin{array}{l}\text { Avaliação } \\
\text { de } \\
\text { Usabilidade }\end{array}$} & \multicolumn{2}{|c|}{$\mathrm{CA}$} & \multicolumn{2}{|c|}{ ID } & \multicolumn{2}{|c|}{ DV } \\
\hline & & $\mathrm{C}$ & B & $\mathrm{C}$ & B & $\mathrm{C}$ & B \\
\hline \multirow{11}{*}{ 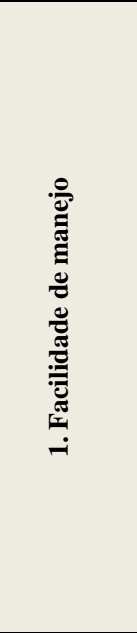 } & Facilidade em vestir & & & & & & \\
\hline & Facilidade em desvestir & & & & & & \\
\hline & $\begin{array}{l}\text { Acionamento dos } \\
\text { aviamentos }\end{array}$ & & & & & & \\
\hline & $\begin{array}{l}\text { Pega e manuseio dos } \\
\text { aviamentos }\end{array}$ & & & & & & \\
\hline & $\begin{array}{l}\text { Exige pouco esforço para } \\
\text { manipulação }\end{array}$ & & & & & & \\
\hline & Materiais dos aviamentos & & & & & & \\
\hline & $\begin{array}{l}\text { Materiais adequados ao } \\
\text { uso }\end{array}$ & & & & & & \\
\hline & $\begin{array}{l}\text { Acabamento dos } \\
\text { aviamentos }\end{array}$ & & & & & & \\
\hline & $\begin{array}{l}\text { Facilidade para } \\
\text { acondicionar }\end{array}$ & & & & & & \\
\hline & Facilidade durante o uso & & & & & & \\
\hline & Mobilidade durante o uso & & & & & & \\
\hline \multirow{4}{*}{ 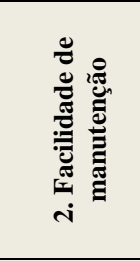 } & Facilidade de limpeza & & & & & & \\
\hline & $\begin{array}{l}\text { Qualidade dos aviamentos } \\
\text { e componentes }\end{array}$ & & & & & & \\
\hline & $\begin{array}{l}\text { Eficácia na limpeza } \\
\text { (permanência de resíduos) }\end{array}$ & & & & & & \\
\hline & $\begin{array}{l}\text { As instruções contidas no } \\
\text { produto são claras }\end{array}$ & & & & & & \\
\hline ल & $\begin{array}{l}\text { A forma do produto, } \\
\text { aviamentos e componentes } \\
\text { sugerem claramente a sua }\end{array}$ & & & & & & \\
\hline
\end{tabular}

$16^{\circ}$ Ergodesign - Congresso Internacional de Ergonomia e Usabilidade de Interfaces Humano Tecnológica: Produto, Informações Ambientes Construídos e Transporte

$16^{\circ}$ USIHC - Congresso Internacional de Ergonomia e Usabilidade de Interfaces Humano Computador

CINAHPA | 2017 - Congresso Internacional de Ambientes Hipermídia para Aprendizagem.

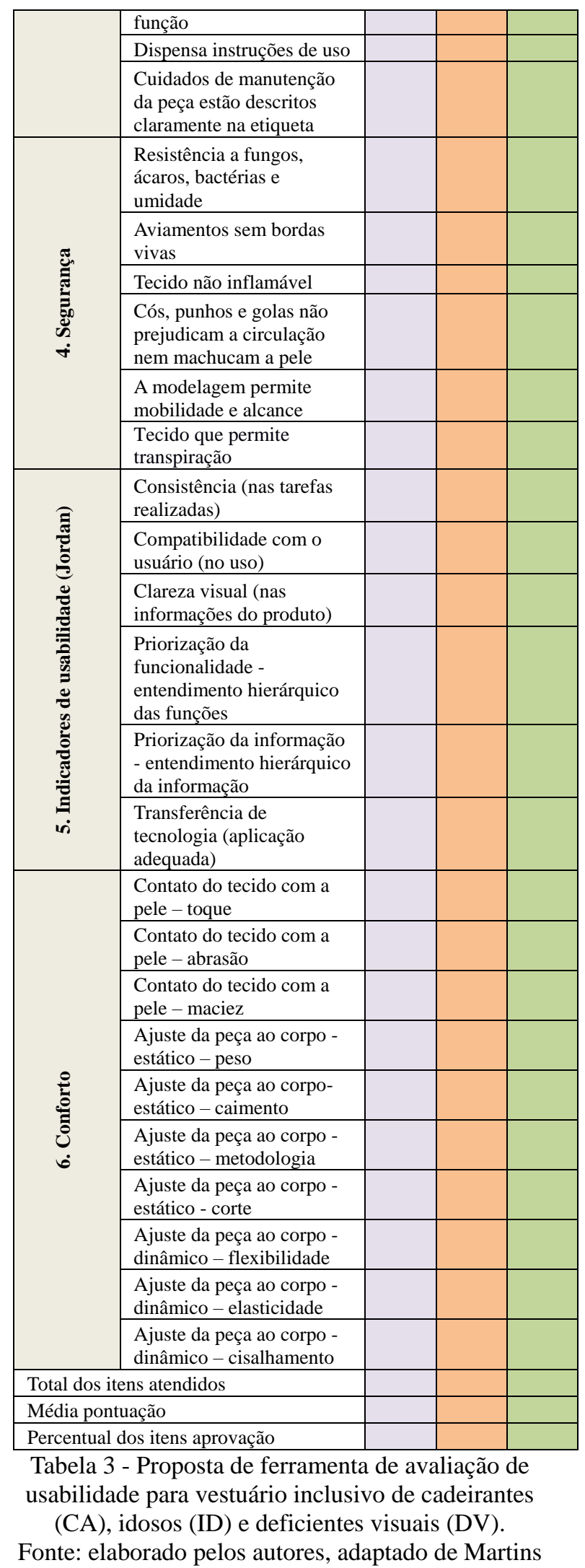




\section{$16^{\circ}$ \\ ERGODESIGN USIHC CINAHPA}

(2008)

As variáveis avaliadas são exatamente as mesmas encontradas em Martins (2008). Os itens avaliados também são os mesmos, senda a calça (letra C) e blusa (letra B). Os indivíduos contemplados, porém, são os cadeirantes (CA), os idosos (ID) e os deficientes visuais (DV). Os itens e as categorias de indivíduos avaliados podem ser modificados conforme a necessidade de cada pesquisador.

Martins (2005) apresenta uma avaliação feita pelos usuários de cada um dos itens do quadro, ou seja, o que cada item avaliado representa na prática do teste com o uso do vestuário, como segue:

1 Facilidade de manejo - foi o requisito com maior índice de itens não atendidos. Foram detectados problemas de manuseio de aviamentos, tais como a pega do zíper, o ajuste e a regulagem do cós das calças.

2 Facilidade de manutenção - em função da calça ser de material sintético, não houve dificuldades com a limpeza e a lavagem, porém os usuários relataram problemas quanto a qualidade dos aviamentos.

3 Facilidade de assimilação - houve dificuldade em assimilar o conteúdo das etiquetas internas das peças. As dificuldades foram em assimilar a composição dos materiais, a simbologia sem texto explicativo e a baixa qualidade na impressão da etiqueta, com letras pequenas e de difícil leitura.

4 Segurança - usuários apontaram inadequação quanto ao botão metálico de pressão utilizado para o fechamento do cós de uma das calças, em função de o material apresentar bordas irregulares.

Também citaram o fato de o botão ficar em contato direto com a pele, causando compressão e irritação da mesma.

O cinto também foi indicado em função da regulagem ser de encaixe por pressão, que ao soltar pode machucar os dedos.

Os bolsos traseiros das calças femininas foram citados por serem excessivamente justos à peça e $16^{\circ}$ Ergodesign - Congresso Internacional de Ergonomia e Usabilidade de Interfaces Humano Tecnológica: Produto, Informações Ambientes Construídos e Transporte

$16^{\circ}$ USIHC - Congresso Internacional de Ergonomia e Usabilidade de Interfaces Humano Computador

CINAHPA | 2017 - Congresso Internacional de Ambientes Hipermídia para Aprendizagem.

não permitirem o armazenamento de objetos, sem o risco de perda.

5 Indicadores de usabilidade - critérios diretamente associados às inadequações das informações de composição dos materiais e cuidados de conservação impressos na etiqueta interna das peças.

6 Conforto - usuários relataram desconforto em relação ao contato do tecido com a pele devido ao material sintético e de tecido plano que dificulta a mobilidade.

A etiqueta interna costurada na peça causou grande desconforto devido à rigidez do seu material em contato com a pele.

Na sequência da coleta dos dados e preenchimento da pontuação de cada item, segundo Martins (2005), o resultado da avaliação deve gerar um conjunto de recomendações para melhoria das inadequações apontadas. Assim, através de uma intervenção ergonômica de correção será possível proceder ao redesign das peças que apresentarem problemas.

\section{Limitações do estudo}

O presente artigo ficou limitado a três categorias de pessoas possíveis usuários de um vestuário adaptado ou vestuário inclusivo, que são os cadeirantes, os deficientes visuais e os idosos com algum acometimento. Entretanto, existem diversos outros grupos de pessoas, com diversos quadros clínicos e outras características, que também podem se beneficiar da metodologia proposta através do uso de peças adequadas às suas necessidades e anseios em termos de vestuário.

Importante salientar também que o checklist é um método prático e que envolve poucos custos para o pesquisador, permitindo identificar rapidamente a existência ou não de requisitos nas peças de vestuário considerados importantes do ponto de vista de diferentes usuários. Para o caso de pessoas com deficiência, é recomendável o seu uso em conjunto com outras métricas que possam complementar as observações, uma vez que 


\section{$16^{\circ}$ \\ ERGODESIGN USIHC CINAHPA}

$16^{\circ}$ Ergodesign - Congresso Internacional de Ergonomia e Usabilidade de Interfaces Humano Tecnológica: Produto, Informações Ambientes Construídos e Transporte

$16^{\circ}$ USIHC - Congresso Internacional de Ergonomia e Usabilidade de Interfaces Humano Computador

CINAHPA | 2017 - Congresso Internacional de Ambientes Hipermídia para Aprendizagem. existem diversas nuances que podem influenciar os resultados.

\section{Considerações Finais}

A interação do ser humano com o vestuário pode ser problemática por diversas razões e em diversos contextos de uso. Essas dificuldades se ampliam quando os usuários apresentam algumas limitações a mais. É nesse contexto que surge o vestuário inclusivo, desenvolvido com o propósito de facilitar a interação das pessoas com deficiência e idosos com o vestuário, porém sem negligenciar os aspectos estéticos e até as tendências de moda em alguns casos.

Cabe resaltar também que muitas das peças desenvolvidas para o vestuário inclusivo podem ser consideradas como peças de Design Universal, uma vez que frequentemente pessoas sem deficiências ao se depararem com um produto inclusivo o consideram superior em diversos aspectos. Daí a importância do estilista ou designer de moda projetar com foco em dois campos primordiais: a estética e os requisitos de usabilidade. Dessa forma, pode tornar-se mais economicamente viável o desenvolvimento de empresas voltadas para o segmento da moda inclusiva, uma vez que seus produtos também sejam adquiridos por consumidores sem deficiência, mas que apreciam peças smart, com mais funções do que as apresentadas atualmente pela indústria.

Nesse sentido, os requisitos e a ferramenta de avaliação de usabilidade para o vestuário inclusivo, podem permitir o desenvolvimento de peças que tragam mais satisfação a todos os usuários, deficientes ou não, que desejem utilizar um vestuário mais prático e funcional. Também permite ao designer de moda projetar com foco no ser humano, minimizando perdas e frustrações aos futuros usuários.

\section{REFERÊNCIAS}

ADANS, N. Empower pack: Natalie Adams looks at the work featured in this year's Design Business Association Design Challenge. Design Week,
Londres, v.17, n. 51, p.14, 19 dez. 2002.

Disponível em:

http://www.designweek.co.uk/news/empowerpack/1106025.article Acesso em: 10 dez. 2014.

BORIN, A. M.; ALMEIDA, F. K. Sistema de identificação de objetos diversos por mensagens de voz utilizando identificação por

radiofreqüência (RFID). 2008. 42 p. Trabalho de

Conclusão de Curso. Curitiba: Universidade

Positivo. Disponível em:

http://www.expounimedcuritiba.com.br/painelgpa/ uploads/imagens/files/EngEletrica/Tcc/tcc_2008/A lmeida_Borin.pdf Acesso em: 28 set. 2016.

BROGIN, B. Gestão de design para moda inclusiva: diretrizes de projeto para experiência do usuário com deficiência motora. 2015. 222 p. Dissertação (Mestrado) - Universidade Federal de Santa Catarina, Centro de Comunicação e Expressão, Programa de Pós-Graduação em Design e Expressão Gráfica, Florianópolis, 2015.

Disponível em:

http://www.bu.ufsc.br/teses/PGDE0094-D.pdf Acesso em: 26 set. 2016.

CARVALHO, O. A. Inclusão social através do vestuário para portadores de necessidades especiais: Uma proposta de intervenção. 2007. 101 p. Dissertação (Programa de Pós-graduação em Moda, Cultura e Arte). Faculdade de Moda. Centro Universitário SENAC. Santo Amaro, São Paulo, 2007. Disponível em: http://livros01.livrosgratis.com.br/cp042174.pdf Acesso em: 10 set. 2013.

CHANG, H. J; HODGES, N.; YURCHISIN, J. Consumers With Disabilities: A Qualitative Exploration of Clothing Selection and Use Among Female College Students. Clothing and Textiles

Research Journal, 2014. Disponível em: http://ctr.sagepub.com/content/32/1/34.full.pdf+ht ml Acesso em: 10 nov. 2015.

COSTA, K. Roupa adaptada à necessidade de deficientes físicos. São Paulo: Portal Aprendiz. 16 mar. 2007. Disponível em:

http://aprendiz.uol.com.br/content/wruspithin.mmp Acesso em: 17 mar. 2011.
Realização:

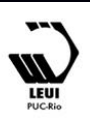




\section{$16^{\circ}$ \\ ERGODESIGN USIHC CINAHPA}

$16^{\circ}$ Ergodesign - Congresso Internacional de Ergonomia e Usabilidade de Interfaces Humano Tecnológica: Produto, Informações Ambientes Construídos e Transporte

$16^{\circ}$ USIHC - Congresso Internacional de Ergonomia e Usabilidade de Interfaces Humano Computador

CINAHPA | 2017 - Congresso Internacional de Ambientes Hipermídia para Aprendizagem.

CUNHA, J.; BROEGA, A. C. Designing Multifuncional Textile Fashion Products. In: AUTEX: WORLD TEXTILE CONFERENCE, 12., Izmir, Turquia, 26/28 maio 2009. Anais eletrônicos... Turquia, 2009. p. 862-868.

Disponível em:

https://repositorium.sdum.uminho.pt/bitstream/182 2/19207/3/AUTEX09_JC_CB.pdf Acesso em: 10 set. 2014 .

JORDAN, P. W. An introduction to usability. London: Taylor \& Francis, 1998.

MAFFEI, S. T. A. O produto de moda para o portador de deficiência física: análise de desconforto. 2010. 90 f. Dissertação (Programa de Pós-Graduação em Design), Faculdade de Arquitetura, Artes e Comunicação da Universidade Estadual Paulista “Júlio de Mesquita Filho". Bauru, SP, 2010.

MARTINS, S. B. O conforto no vestuário: uma interpretação da ergonomia metodologia para avaliação de usabilidade e conforto no vestuário. Florianópolis:

UFSC, Departamento de Engenharia de Produção, 2005. Tese de Doutorado. . Metodologia OIKOS para avaliação da usabilidade e conforto no vestuário. In: $\mathbf{8}^{\mathbf{0}}$ Congresso Brasileiro de Pesquisa e Desenvolvimento em Design, 2008, São Paulo. Anais do $8^{\circ}$ Congresso Brasileiro de Pesquisa e Desenvolvimento em Design.

MATOS, A. L. B. et al. Elaboração de vestuário para portadores de desabilidade física sob a perspectiva do design. In.: ENCUENTRO LATINOAMERICANO DE DISEÑO, Buenos Aires, Argentina, 2007. Anais eletrônicos... Buenos Aires, 2007, p. 1-19. Disponível em: http://fido.palermo.edu/servicios dyc/encuentro20 $\underline{07 / 02 \text { auspicios publicaciones/actas diseno/articu }}$ los_pdf/A6002.pdf Acesso em: 17 mar. 2011.

MEDINA, E. Cabide-visão ajuda deficientes a escolher o vestuário. Imprensa RJ, Rio de Janeiro, 2013. Disponível em:

http://www.rj.gov.br/web/imprensa/exibeconteudo?

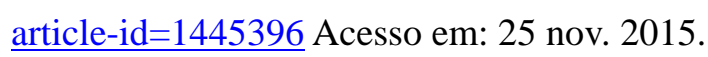

MELO, R. R. Mapa de identificação dos requisitos de projeto de produtos industriais para usuários idosos. 102 p. Dissertação (Mestrado) - Universidade do Estado de Santa Catarina, Centro de Artes, Mestrado em Design, Florianópolis, 2013.

NICOLINI, R. Medida de conforto em Têxteis. In: I CONFERENCIA INTERNACIONAL TÊXTIL/CONFECÇÃO. Rio de Janeiro: Senai/Cetiqt, 1995.

NIELSEN, J. Usability Assessment Methods beyond testing. In: Usability engineering. San Francisco: Morgan Kaufmann, 1993.

PNCE -PACIFIC NORTHWEST COOPERATIVE EXTENSION. Clothing for People With Physical Handicaps. Washington, Idaho, Oregon: PNW222. jan.1983. 25 p. Disponível em:

http://ir.library.oregonstate.edu/xmlui/bitstream/ha ndle/1957/24096/PNWNO222.pdf?sequence=1

Acesso em: 19 maio 2014.

RUBIN, Jeffrey; CHISNEL, Dana. Handbook of usability testing: how to plan, design and conduct effective tests. 2nd ed. Indianápolis: John Wiley \& Sons, 2008.

\section{SMITH, K. B.; DANGIOLO, M. Assistive}

Technologies in the home. USA: Florida State University College of Medicine, 2009. 17 p.

STANTON, N. A.; YOUNG, M. Ergonomics methods in consumer product design and evaluation. In: STANTON, N. A. Human factors in consumer products. London: Taylor \&Francis, 1998.

TULLIS, T.; ALBERT, W. Measuring the user experience: collecting, analyzing, and presenting usability metrics. Burlington: Morgan Kaufman, 2008.

WOLTZ, S. Vestuário inclusivo: a adaptação do vestuário às pessoas portadoras de necessidades especiais motoras. Covilhã, Portugal, 2007.
Realização:
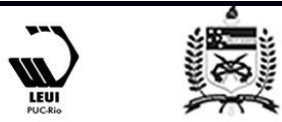


\section{$16^{\circ}$ \\ ERGODESIGN USIHC CINAHPA}

$16^{\circ}$ Ergodesign - Congresso Internacional de Ergonomia e Usabilidade de Interfaces Humano Tecnológica: Produto, Informações Ambientes Construídos e Transporte

$16^{\circ}$ USIHC - Congresso Internacional de Ergonomia e Usabilidade de Interfaces Humano Computador

CINAHPA | 2017 - Congresso Internacional de Ambientes Hipermídia para Aprendizagem.

Dissertação de Mestrado apresentado no curso de Mestrado em Moda e Marketing da Universidade do Minho. Covilhã, Portugal, nov. 2007.

WOLTZ, Silvia; CARVALHO, Miguel Ângelo Fernandes. Vestuário inclusivo: a adaptação do vestuário às pessoas com necessidades especiais. In: $\mathbf{8}^{\mathbf{o}}$ Colóquio de Moda, Novo Hamburgo, 2008. Disponível em:

http://www.coloquiomoda.com.br/anais/anais/4Coloquio-de-Moda_2008/42438.pdf Acesso em: 18 out. 2015.

\section{Agradecimentos}

Agradecimento ao Depto. de Design da Universidade Federal de Santa Catarina - UFSC e a Rede de Pesquisa e Desenvolvimento em Tecnologia Assistiva - Rede T.A. (FAAC/UNESP/Bauru; UDESC; UFPR; UFSC; UTFPR). 